\title{
ENTRAMADO DIALÓGICO Y RASGOS MORFOSINTÁCTICOS EN UN TEXTO CARIBEÑO DEL SIGLO XVIII
}

\author{
Mercedes Román Fernández y Beatriz Gallardo Paúls \\ (Universitat de València)
}

RESUMEN

This article is an attempt of applying the conversational analysis to planned texts through a caribbean work of the 18 th. century called Historia de la conquista de la isla española de Santo Domingo. Trasumtada el año de 1762, del autor dominicano Luis José Peguero.It has been tried to systematize in the conversational analysis a series of elements which characterize the spoken language. This language belongs to a written text which gathered the basic structures and patterns managed in the communicative fact by the speakers, through the intuition of the writer-speaker in which J. L. Peguero became, to transmit his message to his workers.This approach omits the barely socio-linguistical analysis, worried about the kind of the south-western area of S. Domingo speech where this work is settled.On the contrary it has been tried to stay within the real linguistical view, more related to the pragmatics or to the conversational analysis and, thus, make explicit some perceptive realities more or less variable identifying and describing conversational conducts.

\section{Planteamiento.}

Este artículo constituye un segundo intento de aplicar el análisis conversacional a textos planificados a través de una peculiar obra caribeña del siglo XVIII. Por las razones expuestas en B. Gallardo y M. Román $(1994)^{1}$, se consideró que la Historia de la conquista de la isla Española de Santo Domingo trasuntada el año de 1762, del autor Luis José Peguero podía ser el texto idóneo para una comprobación de este tipo.

1 Beatriz Gallardo y Mercedes Román (1994, en prensa): «La aplicación del análisis conversacional a textos planificados: la Historia de la Conquista de L.J.Peguero», en Anuario de Lingüística Hispánica, Universidad de Valladolid. 
El primer intento perseguía en realidad un doble objetivo: que la historia de la lengua pudiera utilizar las aportaciones de las últimas tendencias en lingüística, y que el análisis conversacional se enfrentara a nuevos datos. Esto es, un enriquecimiento tanto en la teoría como en el tratamiento del corpus. En ese trabajo preliminar se planteó, pues, la posibilidad de adoptar un enfoque experimental que permitiese, por una parte, ampliar los estudios diacrónicos al análisis de varios estadios sincrónicos pertenecientes a épocas distintas, tal y como sugieren trabajos fundamentales de Malmberg, Alvar, o Lapesa ${ }^{2}$, y por otra parte, la posibilidad de trasladar esa vertiente histórica a una disciplina como el análisis conversacional, de forma tal que si el modelo explicativo fuese adecuado, resultase válido también en otro tipo de datos.

Si en ese primer artículo se dedicó un especial interés a las peculiaridades de los datos conversacionales que aparecen en el texto de Peguero, en este nuevo trabajo se pretende desarrollar un aspecto diferente: se trata de incorporar las aportaciones de una perspectiva diacrónica al análisis conversacional.

\section{Oralidad-literalidad. Importancia de los textos escritos en la investigación diacrónica.}

No se puede comenzar este artículo sin hacer un somero repaso por algo que en la actualidad parece ya evidente: que los textos escritos son básicos para el conocimiento de la lengua hablada en el pasado y que este hecho implica, necesariamente, profundizar en los documentos históricos que ayuden a desvelar la expresión oral de épocas anteriores. Los estudios con apoyo de textos escritos que se vienen haciendo en América Latina no son tan numerosos como sería de esperar, sin embargo, esta carencia es compensada por la calidad de los mismos. La base central de estos trabajos gira en torno a crónicas, actas, cartas u otros documentos originales de la época colonial y, a través de minuciosos estudios fónicos, morfosintácticos o léxicos, se pretende inferir cómo evolucionó el habla en las distintas regiones americanas ${ }^{3}$.

Los problemas que se derivan del manejo de documentos ha hecho que hasta hace apenas cuarenta años no se dispusiera de documentación fiable en lo que se refiere al español de América: las transcripciones, con relativa frecuencia,

2. B. Malmberg (1967), Los nuevos caminos de la lingüistica, México; M. Alvar (1975), Teoría lingüística de las regiones, Barcelona; R. Lapesa Melgar (1991)»El estudio del español americano en los últimos decenios: aportaciones y cuestiones pendientes» en Actas del III Congreso Internacional de «El Español de América» (1989), Valladolid, pp. 7- 28.

3 Véase entre otros:

- Olga Cock Hincapié (1969): El seseo en el Nuevo Reino de Granada (1550-1650), Bogotá.

- Matriz Fontanella de Weinberg (1982): Aspectos del español hablado en el Río de la Plata durante los siglos XVI y XVII, Bahía Blanca.

- J.M. Lope Banch (1985): El habla de Diego de Ordaz, México.

- Claudia Parodi (1970): «Para el estudio de la lengua traída a la Nueva España» en Anuario de Letras, 8, 1970, pp. 205-218. 
eran modernizadas o, por el contrario, sometidas a gratuitas correcciones arcaizantes. Obviamente, la exactitud no era considerada como un valor prioritario ${ }^{4}$. Serán necesarios trabajos de recuperación como los de Claudia Parodi (1971) ${ }^{5}$ o Peter Boyd-Bowman $(1988)^{6}$ para que los textos nos descubran la presencia de fenómenos como el seseo o el yeísmo en la América del XVI.

Por otra parte, parece evidente que si el estudio de los primitivos estados de la lengua en América es muy interesante, no lo es menos el proceso de consolidación estabilizada y el de la diversificación geográfica que sufrió a partir del XVII. De ahí el excelente recibimiento de trabajos como los de Elena Rojas (1985) y Beatriz Fontanella (1987) en Argentina ${ }^{7}$ o Álvarez Nazario (1982) para Puerto Rico ${ }^{8}$, que se extienden prácticamente hasta nuestros días, permitiendo someter a sus consideraciones el texto de Peguero objeto de estudio en estas páginas.

Todos estos trabajos citados son muy recientes y se centran en textos que manifiestan patentes rasgos de oralidad. De hecho, se puede afirmar que el impulso más fuerte ha surgido en los últimos diez años en torno a lo que Brigit Scharlau (1989) resume como la relación «oralidad-literalidad»: será en el momento de describir situaciones comunicativas concretas cuando esta relación cobre fuerza en favor de la interferencia e implicación mutua entre la lengua hablada y la escrita9. Perspectiva ésta que permite profundizar en la reconstrucción de la lengua hablada a partir de textos escritos, aunque sea preciso establecer siempre aquellas formas presentes en los textos que poseen rasgos de oralidad relevantes. Pero además, una vèz elegido un texto y establecida la intención de reflejar la lengua oral en él, queda por determinar la capacidad de selección del escritor dentro de la gama de rasgos dialectales presentes. Debe observarse que

4. Como ejemplo representativo se encuentra en la Colección de documentos inéditos de América y Oceania. Cf. Rafael Lapesa (1991): «El estudio del español americano en los últimos decenios: aportaciones y cuestiones pendientes» en Actas del III Congreso de el Español de América, 1989, Valladolid, Junta de Castilla y León, pp. 7-29, especialmente p. 9.

5 Claudia Parodi (1971): «Para el conocimiento de la fonética castellana en la Nueva España: 1523. Las sibilantes», en Actas del III Congreso de A.L.F.A.L., San Juan de Puerto Rico, Universidad de Puerto Rico, 1976, pp. 119-131.

6 Peter Boyd-Bowman (1988): «A sample of Sixteenth Century' Caribbean' Spanish Phonology», recogido en Cartas privadas de emigrantes de Indias, 1540-1616, Sevilla, pp. 58-72.

7 Elena Rojas (1985): Evolución histórica del español en Tucumán entre los siglos XVI y $X I X$, Tucumán.

Beatriz Fontanella (1987): El español bonaerense. Cuatro siglos de evolución lingüística (15801980), Buenos Aires.

8 Manuel Alvarez Nazario (1982): Orígenes y desarrollo del español en Puerto Rico (Siglos $X V I$ y XVII), Puerto Rico.

9 Véase Birgit Scharlau (1989): «Oralität, Literalität und der veränderte Blick auf Lateinamerika» en Bild-Wort-Schrift. Beiträge zur Lateinamerika-Sektion des Freiburger Romanistentages, Tubingen, pp. 9-25. 
este punto es fundamental y que el autor puede recurrir a plasmar aquellos que se ajusten más a su interés literario y dejar incompleta la información lingüística, trasmitiendo una realidad sólo parcial.

Pese a las innegables dificultades que presentan los textos escritos, lo cierto es que existe una forma muy fiable de solventar muchas de estas limitaciones: se trata de la comparación con otros testimonios posteriores a los sometidos a examen. Esto es precisamente los que hace, v. gr., Beatriz Fontanella $(1987)^{10}$ con referencia a la lengua gauchesca. Dicha autora establece una relación entre obras que reproducen el habla de los gauchos argentinos y textos documentales que recogen el español bonaerense de los siglos XVIII y XIX ${ }^{11}$. Y así puede concluir que son textos que recogen la voz del pueblo americano y que a través de una lengua no estandarizada quedan reflejados una serie de tipos populares o de grupos étnicos.

En conclusión se puede afirmar que pese a la desconfianza suscitada se ha conseguido, en muchos casos con un éxito ampliamante demostrado, reconstruir realidades lingüísticas propias de la lengua viva ${ }^{12}$.

\section{Transcripción de la oralidad. Tipos de texto.}

Al llegar a este punto conviene hacer un rápido repaso de los diferentes tipos de textos existentes según presenten una u otra intención en la transcripción de la oralidad. Para ello se resume aquí la clasificación básica que hace Birgit Scharlau (1989) de tres clases fundamentales:

1- La llamada oralidad evocada se englobaría dentro de la ficción literaria en la que destacan todos los convencionalismos y tradiciones literarias. El habla aquí reflejada estaría construida artificialmente y por tanto aparecería estereotipada.

2- La oralidad residual recogería el intento de aproximación a la escritura de un hablante de poca formación, así se alejaría de las convenciones para aproximar su expresión a la oral, que le resulta más familiar.

3- Los textos seleccionados que van a servir de base a este estudio corresponderían, por último, al grupo denominado oralidad transcrita, que supone un acto decidido por parte del autor de fijar la lengua oral existente ${ }^{13}$. Como

10 Beatriz Fontanella (1986): «La lengua gauchesca a la luz de recientes estudios de lingüística histórica» en Filología, 21, 1, pp. 7-23.

11 Beatriz Fontanella (1987), op. cit. en nota 7.

12 Y así se tiene constancia, v.gr., del habla bozal caribeña o del cocoliche argentino. Véase al respecto: Germán de Granda (1978): Estudios lingüisticos hispánicos, afrohispánicos y criollos, Madrid; Manuel Alvarez Nazario (1974): El elemento afronegroide en el español de Puerto Rico, S. Juan; Eva Golluscio de Montoya (1979): Etude sur le "cococliche» scénique et edition annotée de "Mateo" d'Armando Discépolo, Toulouse. Muy interesante resulta la reciente publicación de Germán de Granda (1991): El español en tres mundos. Retenciones y Contactos Lingüísticos en América y Africa, Valladolid. 
consecuencia, nos encontramos con cierta ambivalencia en el discurso, que asume al mismo tiempo rasgos contradictorios por definición. En palabras de Boves Naves (1992) ${ }^{14}$ podríamos decir que «el lenguaje vivido se convierte en lenguaje narrado". De ahí que autores como Vicent Salvador $(1991)^{15}$ consideren la oposición entre oralidad y escritura como un continuum comprendido entre dos polos: «des de la més genuïna manifestació de l’oralitat fins a la culminació de la tecnologia de l' escriptura». La tarea del lingüista es discriminar hasta qué punto los dos rasgos resultan compatibles en cada caso dado.

Los textos incluidos en la oralidad transcrita son más tardíos que los restantes. Esto es debido a que se presupone en los autores un dominio de los diferentes registros de manera que los textos reflejan la lengua oral existente; de ahí que surjan ciertas limitaciones en torno a las convenciones literarias ${ }^{16}$, o a la omisión consciente de rasgos pertenecientes a sociolectos inferiores. En todos estos textos (a diferencia del resto de textos escritos), la información contextual es clave, pues ciertos rasgos pueden variar dependiendo del momento histórico o de la finalidad/intencionalidad del autor. En esta línea es donde debe integrarse la obra de Luis José Peguero objeto de este estudio, pues responde a todas las premisas analizadas con anterioridad y puede abrir las puertas al conocimiento de una zona geográfica escasa en trabajos de este tipo, pero, clave para el conocimiento evolutivo del español americano, dado el primordial papel que durante muchos años jugó en la conquista del Nuevo Mundo la isla de Santo Domingo.

\section{La historia de L.J. Peguero: estructuras conversacionales}

Al abordar aquí la Historia de la Conquista, se adopta una perspectiva de lingüística perceptiva en la que se realza uno o más elementos, utilizando al resto como fondo de análisis (López García, 1989) ${ }^{17}$. Esto supone identificar el texto de Peguero, ante todo, como un texto informativo, es decir, con clara prioridad perceptiva de los aspectos semántico-referenciales sobre los aspectos formales o pragmáticos de la lengua. Su intención es contar algo, transmitir un mensaje determinado y con una finalidad concreta. La Historia de la conquista

13 Véase Birgit Scharlau y Mark Münzel (1986): Qellqay. Münddlichr Kultur und Schiftradition bei Indianern Lateinamerikas, Frankfurt-New York, pp. 55-57. En este sentido se debe recordar también las palabras de Peguero cuando reconoce escribir prescindiendo de reglas gramaticales a través de una lengua popular semejante a la que hablan los trabajadores de sus hatos.

14 M.Carmen Boves Naves (1992): El Diálogo, Madrid: Gredos.

1s Vicent salvador Liern (1991): «L'anàlisi del discurs, entre l'oralitat i l'escriptura», en Caplletra ,7 (9-31).

16 Tales como la distribución en párrafos, pausas artificiales... Peguero, muchas veces no las respeta, y se aproxima, de este modo, significativamente a la lengua oral.

17 Ángel López García (1989): Fundamentos de Lingüística perceptiva, Madrid: Gredos 
no es, por eso, un texto monolítico, sino más bien una suma de discursos conectados entre sí por esa finalidad común.

Tal y como se analizó en el trabajo antes mencionado (Gallardo y Román, 1994), el texto se organiza como una sucesión de textos, varios de los cuales adoptan formas dialógicas de distinta configuración. De acuerdo con estas diferencias se distinguieron en su momento tres niveles de «conversacionalidad» en el conjunto de la obra. Evidentemente, el lector actual que se aproxima al texto, no percibe igual una conversación entre Cortés y Moctezuma, que entre Arrio y Mahoma ${ }^{18}$, pues el grado de verosimilitud es distinto (probablemente la verosimilitud fuera equivalente para los coetáneos de Peguero). Pero independientemente de la licencia literaria más o menos arriesgada que suponga la reunión de determinados personajes (en la misma línea encontramos la conversación entre Colón y el pirata Drake), el lector establecerá distinción más notable entre este tipo de discurso y los diálogos que aparecen introducidos dentro de breves narraciones a modo de exempla.

Desde la perspectiva ya clásica del trabajo de Ellinor Ochs $(1979)^{19}$, La Historia de la Conquista refleja un lenguaje planificado, como cualquier obra literaria. André-Larochebouvy $(1984)^{20}$ por su parte, hablaría de un diálogo literario que se distingue por la artificialidad y la fabricación. Pero decir esto, obviamente, supone ignorar la multiplicidad de perspectivas textuales que aborda el libro de Peguero, donde enunciación y enunciado construyen un entramado de riqueza dialógica muy compleja. De ahí la necesidad de establecer niveles distintos de «conversacionalidad», tal y como se apuntaba, para lo que se hablará de conversaciones enmarcadas, conversaciones reproducidas, y conversaciones con el lector.

I. - Las conversaciones enmarcadas se sitúan de pleno en el nivel del enunciado, esto es, lo que cuenta Peguero; se trata de los casos en que la historia relatada incluye diálogos en estilo directo, donde el propio personaje toma la palabra. Los más notables se hallan en las historias de Enriquillo (tomo I pp.189 y ss.), la indiana de Panamá (tomo II pp.85-87), o la de D. Pedro Margarite (tomo I pp.71-72) 21. Son diálogos que reflejan las estructuras narrativas clásicas, orquestadas ya sea desde una perspectiva actancial (trama y actantes) o predicativa (sujeto y predicado). Su función básica es aumentar el dinamismo narrativo, y

i8 Se trata de una serie de diálogos ficticios entre personajes históricos que ocupan una gran parte del libro de Peguero,y que nos van a servir de base para una de las partes de este trabajo.

19 Ellinor Ochs (1979): «Planned and unplanned discourse», en Talmy Givón (ed.) (1979): Syntax and Semantics, 3, New York, Academic Press, pp. 51-80

20 Danielle André-Larochebouvy (1984): La conversation quotidienne, Paris, Credif

21 La primera trata de la sublevación de un cacique local contra los españoles, la segunda hace referencia a los abusos de los virreyes locales, y la tercera se centra en el comportamiento generoso de un oficial español con respecto a sus tropas diezmadas por el hambre. 
refuerzan la versosimilitud de lo expuesto.

II.- Las conversaciones reproducidas no forman parte de ninguna historia, sino que reproducen directamente un diálogo entre dos personajes. La sucesión de voces apenas si se ve interrumpida por la aparición del sujeto de la enunciación, es decir, el narrador. Por el contrario, la técnica es la misma que aparece en tantos otros diálogos literarios, aunque Peguero se decanta claramente por una distribución de papeles asimétrica que lo aproximan a la entrevista. Se trata todavía del nivel del enunciado, pero en lugar de encontrar turnos conversacionales dentro de las historias, se encuentran historias dentro de las intervenciones de un diálogo.

III.-- Por último, las conversaciones con el lector suponen ya una incursión en el nivel de la enunciación, cuando su sujeto (sin entrar aquí en la polifonía que separe a Peguero, al narrador y al autor) interpela directamente a su objeto, esto es, al receptor-lector. Peguero se adelanta siempre a sus posibles reacciones y les plantea algún tipo de objeción o les orienta respecto a la evaluación de las historias que ha ido contando, para que sus conclusiones sean las correctas.

\section{Los papeles textuales y sociales en el enunciado: la información conversacional y marcas morfosintácticas}

\subsection{Negociaciones en los márgenes.}

Las conversaciones enmarcadas que aparecen en el texto se insertan en un discurso exterior a las mismas, de la misma forma que las secuencias constitutivas de una conversación cotidiana aparecen enmarcadas por las secuencias de apertura y de cierre. El presente apartado se fundamenta en este paralelismo del encuadre.

El aspecto concreto que se quiere investigar hace referencia a una serie de fenómenos cuya ubicación más propicia en la conversación cotidiana (pero no

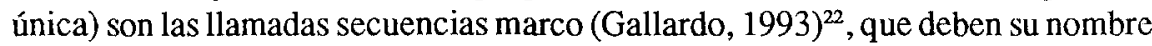
al hecho de aparecer por lo general enmarcando al resto de secuencias conversacionales. Corresponden, pues, a la apertura y al cierre del contacto verbal. Si el trabajo anterior (B.Gallardo y M.Román, 1994) se centraba en las secuencias propiamentente temáticas de las conversaciones, y de manera muy especial en las secuencias de historia, el presente aspecto de la investigación pretende acoger los elementos que no proporcionan una información realmente tópica, sino de otro tipo. De ahí la ubicación general «en los márgenes», aunque convenga recordar que son elementos diseminados a lo largo de cada conversación.

Simplificando mucho la argumentación, se puede decir que desde un punto

22 Beatriz Gallardo (1993): Lingüística perceptiva y conversación: secuencias, Universitat de València- University of Minnesotta 
de vista perceptivo, las secuencias marco establecen una frontera o separación entre la situación de habla y la de silencio, de manera que en la secuencia de apertura esa frontera forma parte de la conversación, y en la de cierre la frontera se realza como elemento del silencio (más especialmente, de la ausencia de conversación, pues se sigue hablando pero ya se ha terminado de hablar). Aunque aquí no hablamos exactamente de una sucesión de intervenciones agrupadas en la realización de una función común, los elementos que interesan son también marginales, ya que no se puede establecer su pertenencia inequívoca a los personajes o al narrador, al dictum o al modus, por utilizar la terminología de Bally.

¿Cómo se plasma este carácter fronterizo en un texto que reproduce conversaciones enmarcadas por verbos dicendi y manifestaciones del narrador?. Evidentemente, dicha frontera nos remite a los límites entre enunciado y enunciación. Los diálogos no reflejan conversaciones enteras (en las que es fácil decir qué turnos se dedican a la apertura y el cierre), pero la labor de encuadre la realizan las oraciones que indican el estilo indirecto. De ahí que, aun situándose en el lugar del marco, no se vaya a hablar de saludos ni despedidas.

De este modo se establece ya una primera puntualización directamente derivada del hecho de aplicar la teoría de análisis conversacional a un texto del XVIII (carente de la espontaneidad oral): la diferente distribución de las informaciones a lo largo del texto.

Las informaciones y significados que se transmiten en todo encuentro dialogado pueden referirse a distintos ámbitos. Por ejemplo, se encuentra la información tópica o temática, que es exactamente aquello que el emisor quiere contar al receptor, o sea, el contenido proposicional de sus emisiones, la estructura narrativa (Polanyi, 1985) ${ }^{23}$ que hace progresar la interacción. Por ejemplo, nos enteramos de lo que Enriquillo le dijo al religioso, y de lo que éste a su vez le respondió, o de cómo reaccionó la indiana ante los requerimientos del virrey:

«Llego una Cuadrilla a donde el padre estava, dixeronle que si hiba por espía de los españoles, a que les respondio que no, que hiba a hablar con Enrique y rogarle que fuese su amigo....(...)»dixo el Religioso, hijo, acuerdate que has de morir, fecundisima es la memoria de la muerte, que acuerda al hombre lo que es, y lo que saca de su simiento la vanidad de las cosas del siglo. Respondio Enriquillo, Padre, del que engaño una ves con Ruin termino, quien se confia del otra vez, no tendra escusa de su daño...» (Tomo I, pp. 192-193).

«...murio en Panamá el tesorero de la Rl. hasienda, y dejo su bella viuda

${ }^{23}$ Livia Polanyi (1985): «Conversational storytelling», en Van Dijk, (ed.) (1985): Handbook of Discourse Analysis, London, Academic Press, pp. 183-202 
mosa y rica, y el Presidente de estaAudiencia la solicito para dama y como la Sra. viuda no lo admitió, le confiscó el caudal y dejola pobrisima, pensando por este medio triunfar de su enteresa; ella dixo que se hiría a España a que su amo el Rey la amparara, lo cual tomo a mofa el Presidente, y todos los dias le mandava dos, y tres recaudos mandandole a preguntar quando se iba a España que la Reina le abia escrito la deseaba conoser para Dama de su corte» (Tomo II, p. 85).

En segundo lugar, hay un tipo de información que se puede llamar estructural o metaconversacional, cuya función es señalar el desarrollo de la propia conversación: caben aquí aspectos como la cesión y toma de turno, las señales de atención continuada (retroalimentación), o los prefacios que advicrten de que el turno en curso durará más de lo habitual. Por lo general es el narrador quien toma la palabra, pero hay casos como el de alguna conversación reproducida, en que es un personaje quien emite estos enunciados metadiscursivos:

«Dejamos a folio 270 a Nro. invicto Colon, y a francisco Drack prestando atencion al Capitulo 15. de la Conversacion de Mahoma y Arrio, y sofocados de oir tantos, y tan descabezados disparates...» (Tomo II, p. 184).

«... pero quien son estos dos...?(...) prestemos silencio $y$ atencion, que hablan de la hamerica, paises que fueron de nuestras delicias." (Tomo II, pp. 163-164).

En tercer lugar, hay un tipo de información sociolingüística que nos proporciona detalles sobre la relación entre los interlocutores, y que se manifiesta muy especialmente a través de las formas de tratamiento, sin utilizar emisiones específicas para explicitar tales significados: 164).

«Mucho plaser e tenido de aber oido a usted señor Colon» (Tomo II, p.

Arrio y Mahoma gozan del desprecio del autor, ferviente católico, entre otros rasgos se manifiesta a través de un constante tuteo:

«y que dizes de Jesuchristo?. en tu Alcoran.

...pero niego( a lo nestoriano)su generacion Eterna; (como la niegas tu, aun con mayor proterbia)» (Tomo II, p. 175).

Desde un punto de vista funcional, lo más importante de las secuencias marco es que los hablantes utilizan su situación marginal para negociar una serie de cosas, desde el tema de la charla hasta la relación social y textual que los vincula. A continuación se analizarán dos de esas negociaciones, teniendo en cuenta si su aparición en intervenciones de enmarque es necesaria, o si por el contrario pueden realizarse en otro lugar, «salpicando» en algún modo el resto de la conversación.

1.- El tema. 
Los turnos iniciales de un intercambio conversacional, por ejemplo, establecen cuál va a ser el tema de conversación, que se introduce tras los saludos, en el «primer intervalo temático» (Schegloff, 1968) ${ }^{24}$. Si, como señala Susan Donaldson $(1979)^{25}$, sólo se puede hablar de conversación cuando se cumple la «regla del tema común», se necesita algún tipo de mecanismo por el cual los hablantes negocien que, efectivamente, van a mantenerse una serie de relaciones de coherencia tópica, es decir, un mínimo de tres intervenciones que deben referirse al mismo tema. Se utilizan para ello los Desencadenantes Iniciales de tema (D.I.T.) identificados por Button y Casey (1984) ${ }^{26}$ tanto en las secuencias de apertura como en los lugares de cambio de tópico (por tanto, cambio de secuencia).

En la p. 129 del tomo I Peguero reproduce un diálogo entre un Colón prisionero del nuevo gobernador de la isla, y su carcelero:

«Le pregunto con mucha tristesa el Almirante vallejo donde me llevais? respondiole, al nabio ba usia, repitio (dudando de ello/Vallejo me hablas verdad, hijo? respondio por vida de Vsa. que es verdad, señor, que se ba a embarcar»

En el texto de Peguero, la negociación sobre el tema de conversación sale efectivamente del ámbito de la conversación en sí, para situarse en el espacio limítrofe que se está describiendo, de manera que es la voz del encuadre, no la de los interlocutores, quien informa del tema. Por ejemplo, en las pp. 163-164 del tomo II, la conversación entre Drake y Colón, se cierra con una intervención de Drake que tiene esta función: da por cerrada una conversación y abre la siguiente:

Mucho plaser e tenido de aber oido a usted señor Colon, estos deslizes, o apuntes de Astrologia, pero quien son estos dos que aqui bienen en combersacion, uno vestido de Militar, y otro desnudo, y tostado del sol?. El Militar es Hernan Cortes, conquistador de la nueva España, y el otro es Moctezuma que fue emperador de aquel basto imperio; prestemos silencio y atencion que hablan de la hamerica, paises que fueron de nuestras delicias.

El carácter marginal de que se viene hablando resulta evidente, pues esta intervención no puede adjudicarse plenamente a ninguno de los dos diálogos; se trata de una información estructural, que no aporta nuevos significados a los que

24 Emanuel Schegloff (1968): «Sequencing in conversational openings», en J.Fishman (ed.) (1968): Readings in the Sociology of Language, The hague, Mouton, pp.91-125.

25 Susan Donaldson (1979): «One kind of speech act: how do we know when we're conversing?», en Semiotica, 28, 3/4, pp.259-299.

26 Graham Button y Neil Casey (1984): «Generating topic: the use of topic initial elicitors», en J. Atkinson y M. Heritage (eds.) (1984): Structures of Social Action, Cambridge, University Press, pp. 167-190. 
han intercambiado Colón y Drake.

También desde el mismo lugar se producen las intervenciones justificativas del narrador, cuando intenta dar razones para la inclusión de determinados pasajes en su libro. Este tipo de afirmaciones (por ejemplo, acerca de lo ilustrativo que puede ser para el lector saber quiénes fueron Mahoma y Arrio, tomo II p. 173) se colocan en una línea próxima a lo que Sinclair y Coulthard $(1975)^{27}$ llaman «transacción», es decir, la parte de la lección que se dedica a pactar cuál será el tema abordado:

«...aunque note el curioso la sacada de estos sujetos del infierno, quiza será por que se sepa quienes fueron, y lo falso y falaz de sus endiabladas setas, para que los Catholico Riamos de sus mal fundadas boberias, haremos un Corto capitulo de ellos, que sirva de grasejo»

\section{2- Los papeles}

Otro de los aspectos que se negocia en las secuencias marco (especialmente las de apertura), son los papeles textuales, los papeles sociales y los papeles participativos tal y como los describe Eija Ventola $(1979)^{28}$, es decir la relacion hablante/oyente, la relación jerárquica o no jerárquica, y la relación ilocucionaria en la que se recoge el inicio y la respuesta.

Parece que lo más interesante en el caso de Peguero es la variedad jerárquica establecida a través de las fórmulas de tratamiento. Aunque este punto se desarrollará más adelante, véase a modo de ejemplo la alternancia pronominal dependiendo de la clase social a la que pertenecen los personajes: en la p. $76 \mathrm{del}$ II tomo un obispo, sin saber que es víctima de la burla de su criado, se dirige primero a unos ordenantes pintados en la pared y después a su camarero. La progresiva indignación del obispo se nota en el cambio de tratamiento: de vos, símbolo de mayor respeto, pasa a tú (con su manifestación americana del plural ustedes, frente al vosotros peninsular):

«dixo enojado, aun todabia no es hora, retiraos; y viendo que no le hasian caso dio vozes diziendo, votenme de aqui estos clerigos (...); acudio a las vozes el camarero y dixo, Señor, que no ha entrado nadie que yo estado a la puerta, solo el indiesillo paje que aun duerme al pie de la cama Ino los vez? dixo el obispo, señalando los retratos; biolos el camarero(...)fuese a ellos y les dizo, cavalleros, vallan fuera, y intentando cojer uno por la mano conocio su engaño, y se rio y dixo al Obispo, señor bea su merce que son travesuras de Antonillo»

27 John Sinclair y Malcolm Coulthard (1975): Towards an analysis of discourse, Oxford University Press.

${ }^{28}$ Eija Ventola (1979): The structure of casual conversation in English», en Journal of Pargmatics, 3 pp.267-298. 
Esta relación jerárquica desaparece en la siguiente historia de la p. 228 del II tomo, pese a que el diálogo se realiza entre el encargado de las viñas y el dueño de las mismas. Tal vez sea debido a que el cargo del empleado no es de simple jornalero sino de un grado superior a éste por lo que el tratamiento será el mismo: vos.

« y preguntandole Este (el Amo) por su viña, dixo el Mayordomo: se la comieron los bueyes, la estropiaron y pisaron, y mataron los mas de vuestros jornaleros:; pues como entraron, dixo el Amo, con unas bayas tan fuertes?. señor dixo el mayordomo, con esta vuestra Orden les abri la puerta: pues vos eres digno de mi indignacion, dixo el amo, y sereis castigado, que la orden no es mia..»

La alternancia entre vos eres y vos ser eis demuestra la confusión del paradigma cuando el hablante de superior jerarquía emplea un tono airado, lo que explicará el tipo de empleo. Para Brown y Gilman $(1968)^{29}$ esta alternancia entre tú y vos se puede producir por un cambio de actitud momentánea. Rafael Lapesa recoge testimionios de este vos disciplente o agresivo durante el siglo XVIII a través v.gr., de Gregorio Garcés (1971) ${ }^{30}$. El criado, como inferior al mayordomo, debería recibir tú como tratamiento. El enfado del superior hace que cambie a vos para acentuar su falta.

Una de las consecuencias directas de esta negociación de papeles (hablante/ oyente en el nivel textual, superior/inferior en el nivel social, inicio/respuesta en el nivel participativo), son las relaciones funcionales entre los hablantes, que para J. Fishman $(1971)^{31}$ quedan ratificadas a través de unas referencias al tiempo, lugar y al dominio (temático).

Para los locativos se puede tener en cuenta la especificación de nombres que identifiquen lugares supuestamente desconocidos para el hablante

«Acaesio que un mansevo español (...) heredo de su Padre un repartimiento de indios que se le dio como a primero conquistador y fundador vezino de la villa de San Juan de Bautista de la Maguana..."

«...que no permitió que sus soldados que comandava en la fortaleza de

29 «The momentary shift of pronoun directly expresses a momentary shift of mood»; Cf.

Brown y Gilman (1968): «The pronouns of power and solidarity» en J. Fishman (ed) (1968): Readings in the Sociology of language, The Hague, Mouton, pp. 252-275, especialmente, p. 274. Por supuesto, este «cambio momentáneo» puede ser consecuencia de un enfado, «the $T$ of comptent and anger is usually introduced between persons who normally eschange $\mathrm{V}$ but it can, of course, also be used by a subordinate to a superior».

30 En 1791 decía: «Del mismo pronombre (vos) nos servimos hablando con inferiores, y de ordinario con alguna suerte de enojo»; Cf. Gregorio Garcés (1971): Fundamentos del vigor y elegancia de la lengua castellana, II, Madrid, 1791, p. 113, citado por Rafael Lapesa (1991): «Formas pronominales...» art. cit. en nota 2, p. 151. Para ejemplos relacionados con el siglo XVI, véase H. Keniston (1937): The syntax of Castilian Prose. The sixteenth century, Chicago, 4.4.24.

31 Joshua Fishman (1971): Sociología del lenguaje, Madrid, Cátedra. 
Las posibilidades de mención para los locativos recorren toda la gama señalada por Schegloff $(1971)^{32}$ : por ejemplo, pueden ser expresiones relativas, a veces con apoyo deíctico para esa relación:

«...en una noche pintó en la pared, frontero de la cama de su amo...» «...que abia Nabio pronto para benir a estos Reinos»

También se puede seleccionar el momento de la historia referido con distintas formulaciones:

«Refierenos el lic.do Don Francisco Xaviel de la Fuente, que el año de 1729 quando su Magestad le hizo la merced de la garnacha..."

«...el año ya pasado del $26 . . . »$

«Amanesio el dia jueves cinco de Julio el mas triste infausto y lastimoso que abistose en esta ciudad»

El carácter marginal ya no es aquí el mismo que en la determinación del tema, pues se trata de informaciones que configuran la llamada estructura descriptiva de las historias (Polanyi, 1985).

\subsection{Los tratamientos y otros mecanismos de selección léxica}

Una tercera característica de las secuencias marco en una conversación cotidiana y completa, es que por lo general se utiliza también para incluir los elementos más propios de la cortesía. Esto no significa, una vez más, que se trate del único lugar donde pueden aparecer. Una disculpa, un cumplido, la más retórica de las afirmaciones, puede encontrarse efectivamente en casi cualquier otro lugar de una conversación, y esto es más cierto si cabe para un texto del siglo XVIII, en el que la cortesía tenía más manifestaciones explícitas que en una conversación actual, donde suele relegarse más al ámbito de lo implícito ${ }^{33}$.

Pero se sigue situando su estudio en un lugar que no es el del enunciado por considerar que la cortesía, en tanto en cuanto ritual de apoyo, constituye un elemento marginal, separado de los aspectos propiamente informativo-referenciales que constituyen la secuencia prototípica de nuestro texto: la secuencia de historia. Lo fundamental para Peguero es la transmisión de una serie de datos y

32 Emanuel Schegloff (1971): «Notes on conversational practice: formulating place», en J.P.Giglioli (ed.) (1972): Language and Social Context, Harmondsworth, Penguin, pp.95-135.

${ }^{33}$ Para un estudio detallado de las formas de tratamiento en el texto desde una perspectiva histórica véase M. Román (1991), «Formas pronominales de tratamiento en el español dominicano del siglo XVIII» en Actas del III Congreso Internacional de "El Español de América (1989)», Valladolid, pp. 341-355. 
argumentos relacionados, y todos los elementos que escapen a este objetivo son elementos aparte. Tal y como se estableció en el estudio anterior, el protagonismo de la secuencia de historia en el libro es tal que afecta a todos los niveles de construcción del texto, tres en concreto:

«- en el nivel de la enunciación, el texto se construye como una narración de historia, es decir, como un tipo concreto de acontecimiento comunicativo,

- en el nivel del enunciado, el texto consta de varias historias o narraciones, muchas de las cuales adoptan una estructura conversacional integrada a su vez por secuencias de historia,

- podríamos hablar incluso de un tercer nivel, desde el momento en que Peguero insiste en sus pretensiones de veracidad e involucra, por tanto, a la Historia con mayúsculas.» (Gallardo y Román, 1994)

En semejante organización, está claro que los aspectos que aquí interesan son aspectos marginales, que actúan como bisagra entre los niveles de la narración. Como ya se indicó, las intervenciones del narrador desde el lugar del enmarque (es decir «desde fuera de lo que cuenta»), funcionan como elemento de coherencia tópica y estructural explicando la disposición y el contenido de los diferentes capítulos. Uno de los mecanismos de categorización que utiliza como tal narrador es la selección léxica, con la que trata de conseguir la identificación adecuada de los referentes por parte del lector.

Para la identificación de los actantes de la historia el criterio básico es aquel que permite el reconocimiento de la persona aludida en la conversación. A veces el nombre sólo es suficiente pero otras veces es precisa una identificación explícita:
«...dejo su bella viuda mosa (.) como la Sra.viuda no lo admitio...» «quiso su buena suerte que un dia que la despedian la vió el infante Cardenal Don Luis Jaymes» «Don Pedro Margarite cavallero catalan» «que un indio criado del ilustrisimo señor Don fr.Pedro Lozada de la Orden Premostratence, obispo de Guatemala...»

Los casos en que se reproduce de una manera más fiel la estructura conversacional se centran en las conversaciones reproducidas, esto es, anotadas directamente sin aparente intervención del narrador ${ }^{34}$. Destacan los diferentes diálogos que reproduce el autor a lo largo de su obra en los que distintos personajes históricos intercambian puntos de vista. Su relación viene determinada, en parte, por las formas de tratamiento cuyo estudio resulta muy interesante. El narrador selecciona un término para caracterizar a una persona en el diálogo e incorpora significados pragmáticos sobre la actitud que mantiene en el relato.

34 Para el análisis detallado de esa estructura, véase Gallardo y Román, 1994, op. cit. 
La información sociolingüística y pragmática que nos llega a través de esta selección léxica, afecta a la relación entre los que hablan en el nivel del enunciado, pero también a cómo son vistos por el sujeto de la enunciación que escribe.

Peguero mantiene el uso respetuoso de vos que había prácticamente desaparecido en España en ese momento. Lapesa $(1970)^{35}$ asegura que era difícil distinguir cuándo reflejaba un habla afectiva y cuándo era un convencionalismo arcaizante. Con todo, Pla Cárceles $(1923)^{36}$ recoge pruebas de la pervivencia de vos en el español hablado: tomo I

- «confio en vos», dice el cacique indio a un capitán español, p.202,

- «asi lo hagais», dice el rey a sus ministros, p. 87, tomo II.

Drake se dirige a Colón tratándole de usted y éste se ofende. Se debe señalar que el pirata inglés no goza de las simpatías del autor dominicano, p.150, tomo II,

- «(...) y pues he hallado aquí a usted, pareseme que le haré plaser»

- «hableme con mas Respecto, Drak (...) que no semos de igual graduacion»

Entre Mahoma y Arrio p. 174, tomo II, la fórmula es siempre $t u ́$ pues el autor siente un profundo desprecio por los dos personajes:

- «De que te sirvio la mucha hasienda de esta viuda?»

— «Tu me hablas de esa Manera por que no soy filosofo como tu»

De $t u ́$ se trataban aquellos que mantenían una relación de confianza, pero también era reservado para la conversación con inferiores ${ }^{37}$. Indudablemente, Peguero mezcla ambos usos para rebajar a sus personajes. Sólo se observa una alteración en este tuteo constante. Al finalizar la conversación, Mahoma, que ha sido objeto de crueles comentarios, ironiza sobre la historia de Arrio:

«Deseara saber su historia enteramente y le estimara me la refiera, por que crea usted que si el ignorante autor de estos borrones la hubiera leído, la sacara como la Mia a ser Risa de sus campesinos».

Este repentino uso del usted respetuoso junto con el pronombre de tercera

35 «Personas gramaticales y tratamientos en el español» en Homenaje a Menéndez Pidal, IV, Revista de la Universidad de Madrid, 19, 1970, pp. 149-156, especialmente p. 151.

36 «A través de Gregorio Garcés, quien en 1791, señalaba en su Fundamento del vigor y elegancia de la lengua castellana, que «del pronomnbre vos nos servimos hablando con inferiores y de ordinario con alguna suerte de enojos; cf. Pla Cárceles (1923): «La evolución del tratamiento 'vuestra merced'», en Revista de filología Española, X, p. 247.

37 Véase Rafael Lapesa (1970, p. 145); Keniston (1937, pp. 42-43) 
persona, le, refleja la ira de Mahoma. El pronombre de tercera persona ya era recogido por Correas como símbolo de enojo o desprecio ${ }^{38}$, también significaba cortesía vulgar y con él se negaba al interlocutor otro tratamiento superior. El comienzo del parlamento conlleva, por tanto, un insulto hacia Arrio.

Sólo utiliza Peguero una vez más el pronombre de tercera persona, cuando en la página 152 del tomo II, Drake interroga a Colón:

« ¿lo dejaron ocioso en España, despues de estos dos biajes a la America?».

La alternancia $t u ́$-vos por causas afectivas se refleja en dos ocasiones más. La primera se produce entre Colón y Drake. En la página 151 del II tomo, durante una conversación que no se caracterizaba por su cordialidad, ambos interlocutores emplean vos, asumiendo así una relación de igualdad:

\section{Colón — Mirad, en un Cuerpo de infanteria (...) ay muchos capitanes expertos» \\ Drake — «Vos, mucho plazer me habeis dado»}

Poco después, sin embargo, Colón asume un tono autoritario para aconsejar al inglés. Colón se considera superior a Drake, de ahí que se permita estas licencias ${ }^{39}$ :

"Oyeme atento te dire con anterioridad, de paso, que es la embidia" «no as podido trabajar en la Geografía»

En la segunda ocasión, los interlocutores son Cortés y Mocteuma. En la página 164 del II tomo, Cortés emplea tú para dirigirse al rey azteca ofendido por una lección de historia comparada que acaba de recibir ${ }^{40}$ :

«Quien te ha dicho tanto del Capitulo de los Atenienses que no conosiste?»

Poco después es Moctezuma el que se siente molesto por los comentarios vejatorios de Cortés hacia la capacidad militar de los indios y le contesta:

38 Correas, Arte de la lengua..., «quando nos enoxamos i reñimos con alguno le tratamos de él, y de vos por desden», citado en Lapesa (1970) «Personas gramaticales...», p. 159.

39 El poder que una persona ejerce sobre otra se explica, según Brown y Gilman, cuando uno puede controlar el comportamiento del otro. Normalmente, el que ejerce el poder se permite variar el tratamiento y otorgar uno inferior al que venía utilizando.

40 Cortés: «ustedes señores Americanos eran bien groseros»

Moctezuma: «Digame usted por su vida, si los Atenienses eran hombres de entendimiento?»

Cortés asiente y Moctezuma le recuerda el engaño del tiraño Pisístrato quien fingió la aparición de la diosa Minerva para aconsejar a los atenienses que le volvieran a aceptar. Cf. Historia de la conquista..., pp. 164-165, II tomo. 
El hecho de que estos hablantes se retiren el tratamiento de cortesía entre iguales, es decir, vos, refleja un cambio de actitud y un intento de establecer un distanciamiento: ambos se creen superiores al otro.

Brown y Gilman (1968) señalan que puede haber otros condicionamientos en el cambio de actitud, reflejo, v.gr., de un carácter particularmente cruel ${ }^{41}$. En la página 118 del II tomo, Peguero cuenta los abusos de un virrey que castiga injustamente a unos ciudadanos principales. El pueblo protesta y hay represalias. Uno de los condenados, caballero de edad avanzada, pide clemencia y el virrey contesta mientras le golpea:

\section{«ahora lo veras»}

Al retirarle el vos, que por dignidad le corresponde, pretende rebajarle socialmente y como consecuencia existe un insulto implícito en esta actitud.

El uso del pronombre $t u ́$ de segunda persona, puede deberse a otras causas tales como la diferencia de edad o la relación familiar ${ }^{42}$. En la página $60 \mathrm{del}$ tomo I, Colón es llevado como prisionero a un navío y mantiene una conversación con el capitán. Las circunstancias que le rodean son especiales: Colón ignora su destino, tiene miedo, pero sobre todo, existe una notable diferencia de edad entre los dos hombres.

$$
\begin{aligned}
& \text { Colón- ¿Dónde me llevais } \\
& \text { Capitán- «Al nabio ba usia» } \\
& \text { Colón- ¿Me hablas verdad, hijo?» }
\end{aligned}
$$

Colón siente una repentina simpatía por el joven que le habla con tanto respeto y le otorga el tú como símbolo de consideración afectiva.

Un ejemplo similar encontramos en la página 153 del mismo tomo. El cacique indio Enrique se ha sublevado contra los españoles. Aunque recibe siempre vos de sus interlocutores, una excepción la constituye el sacerdote que le educó en su infancia.

\section{«Dixo el religioso, hijo, acuerdate que has de morir»}

Obviamente, existe un rasgo afectivo entre estas dos personas que permiten

41 «The fact that a man has a particular momentary attitude or emotion may imply a great deal about his characteristic disposition, his readiness for one kind or feeling rather than another». Cf. Brown y Gilman (1968, p. 274).

42 Véase Rafael Lapesa (1970, p. 145); Keniston (1937, pp. 42-43).

43 Ya Correas señalaba que «de tú se trata a los muchachos i menores de la familia, i a los que 
a la de más edad el empleo de un tuteo familiar ${ }^{43}$.

El último caso que se registra en Peguero con respecto a la alternancia tú-vos, se produce entre un español y su esposa india:

«Si me guardas secreto para con tus Españoles, yo te curare en breve tiempo, pero sabed, que en cuanto me descubras yo morire y me mataran mis parientes, que no quieren que ustedes sepan el como se cura este mal por ber si mueren todos (...) Pues sabed que este es un contagio que fácilmente se pega, y assí, os separad de mi y de vuestros hijos hasta que os cure»

La esposa se dirige a su marido empleando indistintamente tú y vos sin aparentes razones que lo motiven. Esta mezcla está àmpliamente atestiguada en las lenguas romances, y como señala Rafael Lapesa, «tiene como antecedente el fácil tránsito de un tratamiento a otro dentro de una misma frase o frases vecinas ${ }^{44}$.

$T u ́$ como fórmula de cortesía sin alternancia con otro pronombre se registra en la siguiente ocasión:

\section{«en que te ofendi? Dios te perdone»}

exclama un antiguo virrey ahora encarcelado, p.117, tomo II. Aunque despojado de su dignidad, el virrey sigue dirigiéndose a un inferior con $t u ́$, sea o no su verdugo. Pero tal vez el caso más interesante sea la conservación del alocutivo su merced en boca de una esclava negra que se dirige a un mulato adinerado. Situado en un relato contemporáneo al autor, p.258, tomo II:

«no me acuerde su merce que tube mi primer hijo Gregorio en quien tenia todas mis esperanzas»

Tradicionalmente este uso se hã circunscrito al ámbito rural, en particular al habla de los negros. Ya en el siglo XIX, significaba el respeto entre iguales, posiblemente debido al abandono de esta fórmula por los esclavos negros después de su liberación, producida en 1822. Sin embargo, se debe hacer notar que Peguero, 100 años antes, coloca en boca de personas de similar condición este alocutivo.

Tras este somero análisis podemos concluir que el espectro de las fórmulas de cortesía empleado por Peguero es muy amplio. El texto presenta una serie de peculiaridades muy interesantes, características del habla dominicana en los sociolectos populares durante el siglo XVIII.

se quisiere bien». Cf. en Arte de la Lengua castellana, ed, Alarcos, p. 363, citado por Rafael Lapesa (1970) en «Personas gramaticales...», p. 159, nota 60.

44 Cf. art. cit. en nota 22, p. 153. 


\subsection{Selección verbal}

Las historias aparecen en la conversación como si fueran la consecuencia inevitable del habla en curso, y es evidente que suponen un acto de voluntad por parte del hablante que las relata, independientemente de que aparezcan motivadas por la solicitud de otro participante o, simplemente, por iniciativa del narrador que desea contarlas o dar una explicación de una conducta conversacional inmediata. Cuando se cuenta algo, se habla de algo que ha pasado y los acontecimientos se sitúan en un tiempo anterior al relato, de ahí que las historias tengan una ordenación cronológica con dos tiempos: el antes y el después. Lo realmente interesante es el carácter perfectivo con el que el hablante organiza los hechos relatados: es decir, el principio y el fin del relato que constituye su ordenación cronológica es lo que conforma las secuencias de historia y esto será lo que permita un cambio de estado o de transformación ${ }^{45}$.

Se debe recordar que en la estructura narrativa se encuentran las cláusulas de acción. En ellas el narrador deja constancia de los hechos principales de la historia. Generalmente su progresión es, como ya se sabe, temporal, y en opinión de Polanyi (1985) se identifican fundamentalemnte por la frecuente presencia de pretérito perfecto:

«dejo su bella viuda»
«no lo admitio»
«y se le respondio»
«todos dixeron»
«e levanto y solto las tortolas»

Por su parte, B. Johnstone ${ }^{46}$ analiza narraciones de conversaciones naturales y establece una relación entre el estatus de los protagonistas y la selección temporal en los verbos dicendi. Esta interacción verbal se produciría de la siguiente manera:

- el presente o la ausencia del verbo dicendi para el personaje marcado de autoridad;

- el perfecto para el personaje no marcado por la autoridad.

En el relato de la indiana, p. 87, tomo II, que pide justicia al monarca español ante los abusos de su virrey en Panamá, el rey cuando habla lo hace siempre en pasado:

«y por complaser mas a la Reyna la dixo»

Ahora bien, la indiana le responde en ese mismo tiempo para referirle las injusticias que comenten sus delegados de Indias

«y puesta de rodillas a sus reales plantas le dixo, mi Rey, mi amo...»

45 Como señala M. Stubbs (1983): Análisis del discurso. Análisis sociolingüístico del lenguaje natural, Madrid, 1987, p. 38, «las historias no se paran, sino que se terminan».

46 Barbara Johnstone (1987): «He says... so I said»: verb tense alteration and nartative 
El verbo también se introduce en pasado en el diálogo entre Colón y Drake. Aunque, como se ha visto, existía una diferenciación social entre ellos, por tanto se puede adoptar aquí cierta ampliación, y suponer que la presencia del presente está motivada por un deseo de actualización de la historia que no guarda necesariamente relación con el estatus de los protagonistas. Así en la introducción de la noticia puede aparecer el perfecto, es decir, el tiempo no marcado para el relato.

«(...) Colon estava reposando (...) quando bió benir asi a el valiente Capitan (...) francisco Drak y le dixo»

Mientras que el presente aparece ya cuando se quiere potenciar el enunciado, es decir, cuando se quiere destacar un elemento de la historia. De esto último no se ha encontrado ningún ejemplo en estas páginas tal vez debido al carácter histórico del texto, sentido como algo pasado en la conciencia del narrador.

\section{6.- Conclusión}

Se ha intentado sistematizar dentro del análisis conversacional una serie de elementos que caracterizan el lenguaje hablado. Este lenguaje forma parte de un texto escrito que ha sabido recoger las estructuras y los patrones básicos que los hablantes manejan en el acontecimiento comunicativo, a través de la intuición del escritor-conversador ${ }^{47}$ en que se convirtió Peguero para hacer llegar su mensaje a sus trabajadores. Este planteamiento prescinde del análisis propiamente sociolinguiístico, preocupado por la modalidad del habla del área suroccidental de Santo Domingo donde se inscribe esta obra. Por el contrario, se ha pretendido permanecer dentro del panorama lingüístico actual más vinculado a la pragmática o el análisis conversacional y, así, explicitar unas realidades perceptivas, más o menos modificables, identificando y describiendo conductas conversacionales.

El aspecto más notable que cabe señalar es la orquestación de los diferentes niveles conversacionales a lo largo del texto, creando espacios fronterizos entre la enunciación y el enunciado que el autor aprovecha para introducir las informaciones estructurales o metaconversacionales: presenta a los personajes, introduce el tema de conversación... Las informaciones sociolingüísticas, que nos informan por ejemplo sobre la relación social entre los hablantes, o sobre la concepción que el autor tiene de sus personajes, se vehiculan a través de rasgos superficiales como la selección pronominal o verbal. A la vez, el cruce que se da entre los tres niveles del discurso (enunciación, enunciado, y frontera entre ambos) es constante, creando una situación dialogada de extraordinaria complejidad.

depictions of authority in American English sen Linguistics, 25, pp. 33-52.

47 La estructura evaluativa como «marca de la enunciación» a través de la cual Peguero se filtra y determina en uno u otro sentido la recepción. 